\title{
Sliding Shape Extraocular Muscle Transposition with Plication: A Novel Method
}

\author{
Birsen Gokyigit, (ㄱ) Asli Inal, (ㄱ) Bulut Ocak, (1) Ebru Demet Aygit
}

Department of Ophthalmology, University of Health Sciences Beyoglu Eye Training and Research Hospital, Istanbul, Turkey

\begin{abstract}
Objectives: This study aims to present a novel operation method of delivering both vascular protection and strengthening of the muscles, as well as the transposition of the muscles.

Methods: The patients' files were scanned retrospectively. All patients underwent a complete eye examination in addition to motility examination, both preoperatively and postoperatively. Patients were followed up at least six months. Pre- and post-operative deviation measurement values were compared statistically. Operation technique: After being exposed and the rectus muscle was freed from the facial structure as far as planned resection amount. 6-0 coated vicryl sutures were then placed through the two sides of the muscle while protecting the blood vessels. Then, each suture was placed close to the muscle insertion and was aimed at transposition side. For example, if the target was to transpose the superior rectus at the temporal side, nasal side suture was placed at temporal edge of muscle insertion, and temporal side suture is placed approximately a tendon width laterally to the insertion.

Results: In patients who were planned resection $7 \mathrm{~mm}$ and over, the procedure for complete muscle widening transposition was successful. Only $2 / 3$ transpositions could be achieved in four patients who underwent less than $7 \mathrm{~mm}$ of strengthening. There was no anterior segment ischemia in three patients who underwent three rectus muscle surgery in the same eye.

Conclusion: 'Sliding shape' design extraocular muscle plication found a simple, safe and effective procedure for patients who needed resection and transposition operation. More patients and longer follow-up are needed to understand the real effectiveness.
\end{abstract}

Keywords: Extraocular muscles, sliding shape transposition, strabismus, vessel protection

\section{Introduction}

In some indications, for example, monocular elevation deficiency (MED) with horizontal deviation, patients need three muscles surgery in the same eye $(I, 2)$. In the treatment plan, one muscle needs both transposition procedure with resection and the blood supply protection for preventing anterior segment ischemia (2). Taking these needs into account, we have developed an effective method of delivering both vascular protection and strengthening of the muscles, as well as the transposition of the muscles.
The present study aims to present a novel operation method of delivering both vascular protection and strengthening of the muscles, as well as the transposition of the muscles.

\section{Methods}

There were 12 patients operated on with this new technique. The patients' files were scanned retrospectively. All patients underwent complete eye examinations, both preoperatively and postoperatively. Patients were followed up at least six months. For statistical evaluation, SPSS for windows 16 program was used for pre- and post- operative deviation

Address for correspondence: Bulut Ocak, MD. Beyoglu Goz Egitim ve Arastirma Hastanesi, Saglik Bilimleri Universitesi, Oftalmoloji Anabilim Dali, Istanbul, Turkey

Phone: +90 5334122179 E-mail: bulutocak@gmail.com

Submitted Date: July 08, 2019 Accepted Date: July 28, 2019 Available Online Date: August 09, 2019

${ }^{\circ}$ Copyright 2019 by Beyoglu Eye Training and Research Hospital - Available online at www.beyoglueye.com OPEN ACCESS This work is licensed under a Creative Commons Attribution-NonCommercial 4.0 International License. 
measurements compartment. Shapiro Wilk test was used for the normality test. Mann-Whitney $U$ test was used for statistical evaluation. P-value of less than 0.05 accepted as meaningful.

\section{Operation Technique}

After being exposed and the rectus muscle was freed from the facial structure as far as planned resection amount, either double-armed 6-0 coated vicryl sutures were placed through all length of the muscle or two separate sutures in the two sides of the muscle while protecting the blood vessels (Fig. Ia). Then, each suture was placed to the muscle insertion and was aimed at transposition side. For example, if the target was to transpose the medial rectus at the superior side, inferior side suture was placed at the superior edge of muscle insertion (Fig. Ib) and the superior side suture was placed approximately a tendon width superiorly to the insertion (Fig. Ib). During the transposition procedure, if we aimed to treat MED, superior edge scleral suturation was done according to Thillaux spiral and toward to superior rectus insertion. If our goal was to treat a pattern deviation, the superior edge must be put in the same direction of the horizontal muscle insertion. We added one $6 / 0$ white dacron sutures in the middle of the plication in our last six patients. (Fig. Ic) The reason was to try to keep the middle of the muscle at the same level with two edges and protect postoperative results.

\section{Results}

Patients' demographical information, preoperative findings, plication amounts, and plication sides are shown in Table I. In patients who were planned resection $7 \mathrm{~mm}$ and over, the procedure for complete muscle widening transposition was successful. Only $2 / 3$ transpositions could be achieved in four patients who underwent less than $7 \mathrm{~mm}$ of strengthening. (Case no 4,9,10,II) There was no anterior segment ischemia in three patients (Case no I, I0, II) who underwent three rectus muscles surgery in the same eye. All parameters were statistically significant $(p<0.05)$ between pre- and post- operative measurement values. The results shown are in Table 2.
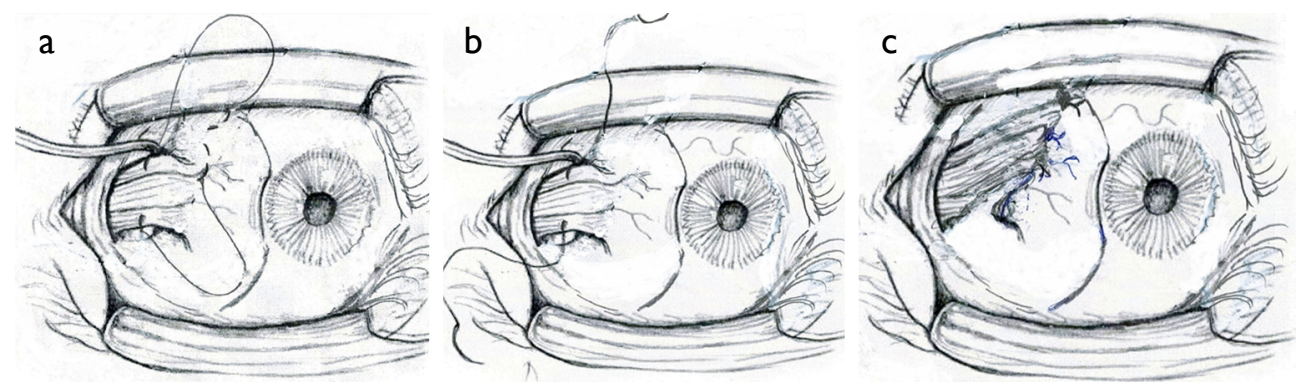

Figure I. (a) Two separate sutures in the two sides of the muscle. (b) Transposition and plication of the extraocular muscle. (c) Added one dacron sutures in the middle of the plication of the muscle.

Table I. Patients' demographics, preoperative deviations, plication features

\begin{tabular}{lcccccc} 
No & Age & Gender & Deviation (pd) & Muscle & Plication & Slide side \\
\hline I & 12 & Male & CEOMF 25 XT 8 L/R & MR & $6 \mathrm{~mm}$ & Supra \\
2 & 4 & Male & 35 ETV pattern & LR & $7 \mathrm{~mm}$ & Supra \\
3 & 54 & Female & 25 XTV pattern & MR & $6 \mathrm{~mm}$ & Infra \\
$4^{*}$ & 43 & Male & I6 XT A pattern & MR & $5 \mathrm{~mm}$ & Supra \\
5 & 3 & Female & 20 ET I2 L/R & LR & $7 \mathrm{~mm}$ & Supra \\
6 & 30 & Male & 40 XTV pattern & MR/ MR & $8.5 / 6 \mathrm{~mm}$ & Infra \\
7 & 27 & Male & 40 XT I2 L/R & MR & $7 \mathrm{~mm}$ & Infra \\
8 & 49 & Male & 30 ET I8 L/R & LR & $7 \mathrm{~mm}$ & Infra \\
$9 *$ & 11 & Female & I0XT I0 L/R & IR & $3 \mathrm{~mm}$ & Nasal \\
$10^{*}$ & 17 & Male & 20 XT I4 R/L A patt. & IR & $5 \mathrm{~mm}$ & Nasal \\
II* & 9 & Female & 30 ET Left MED & MR & $5 \mathrm{~mm}$ & Supra \\
12 & 60 & Male & I4 ET 6 R/L & LR & $6 \mathrm{~mm}$ & Supra \\
\hline
\end{tabular}

Pd: Prism diopter; CEOMF: Congenital extra-ocular muscle fibrosis; XT: Exotropia; L: left; R: right; MR: medial rectus; ET: Esotropia; LR: Lateral rectus; IR: Inferior rectus; MED: Monocular elevation deficiency. 
Table 2. Pre- and post- operative findings

\begin{tabular}{lcccc} 
No & I. Deviation (pd) & 2. Deviation (pd) & Improvement (pd) & Follow-up \\
\hline I & CEOMF 25 XT 8 L/R & 12 XT & 13 hor.8 vert. & $8 \mathrm{~m}$ \\
2 & 35 ETV pattern & 16 XT & 20 hor. Min pattern & $6 \mathrm{~m}$ \\
3 & 25 XTV pattern & Orthotropic & 25 hor no pattern & $10 \mathrm{~m}$ \\
4 & 16 XT A pattern & Orthotropic & 16 hor no pattern & $8 \mathrm{~m}$ \\
5 & 20 ET I2 L/R & 2 L/R & 20 hor 10 vert & $8 \mathrm{~m}$ \\
6 & 40 XTV pattern & 25 XT no pattern & 15 hor no pattern & $18 \mathrm{~m}$ \\
7 & 40 XT I2 L/R & 2 R/L & 40 hor 10 vert & $8 \mathrm{~m}$ \\
8 & 30 ET I8 L/R & 8 L/R & 30 hor 10 vert & $6 \mathrm{~m}$ \\
9 & 10 XT I0 L/R & 4 XT & 6 hor 10 vert & $12 \mathrm{~m}$ \\
10 & 20 XT I4 R/L A pattern & Orthotropic & 20 hor 14 ver no patern & $14 \mathrm{~m}$ \\
II & 30 ET Left MED (-4) & Orthotropic $(-2)$ & 30 hor $(+2)$ vert & $11 \mathrm{~m}$ \\
12 & I4 ET 6 R/L & 2 ET & 10 hor 6 vert & $18 \mathrm{~m}$ \\
\hline
\end{tabular}

Pd: Prism diopter; CEOMF: Congenital extra-ocular muscle fibrosis; XT: Exotropia; L: left; R: right; MR: medial rectus; ET: Esotropia; LR: Lateral rectus; IR: Inferior rectus; MED: Monocular elevation deficiency.

\section{Discussion}

Treatment of $A$ and $V$ pattern strabismus without oblique muscle dysfunction is possible with horizontal muscles vertical transposition. This is a well-known method in classical textbooks. And also, Knapp procedure, and so on, provides a shifting of the globe in a certain direction via muscle transposition. During strabismus operation, which required muscle transposition, often three rectus muscles operation are involved in the plan, which threatens anterior segment blood supply. On the other hand, plication operation has a specific value for protecting the anterior segment blood supply as well as a similar effect with resection $(I-4)$.

It is not included in an operation technique or similar ophthalmology literature, as mentioned in this study. Similar shifts to the muscles are more commonly seen in the orthopaedic literature. Thus, there is no example in which we can make a comparison in the discussion. We introduced the method in AAO 2017 meeting as a poster presentation and also in ESA meeting in the same year. This presentation was placed in ESA transaction book $(5,6)$.

\section{Conclusion}

Sliding shape design extraocular muscle plication found a simple, safe and effective procedure for patients who needed resection and transposition operation. More patients and longer follow-ups are needed to understand the real effectiveness.

\section{Disclosures}

Peer-review: Externally peer-reviewed.

Conflict of Interest: None declared.

Authorship Contributions: Involved in design and conduct of the study (BG, BO); preparation and review of the study (BG, $A \mathrm{i}$, EDA); data collection (BO, Ai, EDA); and statistical analysis (EDA).

\section{References}

I. Sonwani P, Amitava AK, Khan AA, Gupta S, Grover S, Kumari N. Plication as an alternative to resection in horizontal strabismus: A randomized clinical trial. Indian J Ophthalmol 2017;65:853-8.

2. Nihalani BR, Hunter DG. Adjustable suture strabismus surgery. Eye (Lond) 20I I;25: I262-76. [Crossref]

3. Oltra EZ, Pineles SL, Demer JL, Quan AV, Velez FG. The effect of rectus muscle recession, resection and plication on anterior segment circulation in humans. $\mathrm{Br} \mathrm{J}$ Ophthalmol 2015;99:556-60. [Crossref]

4. Chaudhuri Z, Demer JL. Surgical outcomes following rectus muscle plication: a potentially reversible, vessel-sparing alternative to resection. JAMA Ophthalmol 20 I4; I32:579-85. [Crossref]

5. Gokyigit B, Inal A, Ocak OB, Aygit ED, Celik S. 'Sliding shape' extraocular muscle plication: Novel Technique. [Poster Presentation] Annual meeting programme and floor plan of AAO. New Orleans:2017;128.

6. Gokyigit B, Inal A, Ocak OB, Aygit ED, Celik S. 'Sliding shape' extraocular muscle plication: Novel Technique In: DE Cioplean (ed). Transaction of the 39th. Meeting of ESA: Porto; 20I7; II3-5. 